\section{Vegetarianism in War-time}

So closely is vegetarianism linked in many minds with food 'faddism' that one runs the risk of being regarded as eccentric if the consumption of more vegetables is strongly advocated. Nevertheless, the slogan 'Eat more Vegetables' is not only to form a central feature of the nutritional policy of the Ministry of Food during the War, but also, it is hoped, will be prominent in the post-War campaign to erradicate malnutrition from Great Britain. One simple fact stands out. Wholemeal cereals, vegetables, potatoes and milk or cheese provide all that is required for building a sound body and for maintaining good health. A little book of useful recipes, written primarily, one imagines, for vegetarians, entitled "Food in War-Time" (edited by W. H. White. London: G. Bell \& Sons, Ltd., in conjunction with the London Vegetarian Society, 1940. 6d. net), should be widely read and used. It describes many dishes which would be valuable additions to our diet in ordinary times as well as in the special times for which it has been written.

\section{Plastic Materials in the Yankee Clipper}

A LARGE amount of plastic materials is used in the construction and furnishing of the American machines of the Yankee Clipper class, used in the trans-Atlantic air service. According to an article in the Electrician of March 8, colour plays an important part in the furnishing and decoration of these machines. The average American traveller is very critical of his travel-surroundings, and as he is relatively a prisoner in the machine for long hours on end, it is essential that his liking for cheerful surroundings be satisfied. Plastic decorations have been found to be most useful by the designers.

The dining-room has dome lights made of cellulose and giving a diffused light. The rear compartment, sometimes known as the 'bridal suite', is very luxurious, and is furnished with a dressing-table, ete. The lighting around the dressing-table has shades made of another type of cellulose acetate material. The dressing-table top is of synthetic resin laminated material. On the other hand, the wash-basins and table-tops in the ladies' dressing-room are in a blue vinyl material. The upper wall fabric is protected. with sheets of transparent methyl material. Similarly, the cabin windows and the navigator's turret are 'glazed' with methacrylate. Plastic materials are also used for passenger signal flashing lights, for fuel tank gauges, and for some of the control knobs. The walls are made of opaque vitryl resin sheets, differing in colour in the various cabins and departments. Laminated material is used for some of the control pulleys, for spacers of various kinds and for certain bushings, and plastic materials form the basis of most of the paint and lacquer used on the machines.

\section{The National Institute of Agricultural Botany}

THe annual report of the National Institute of Agricultural Botany, Huntingdon Road, Cambridge, for the season 1938-39 has been issued. Much of the Institute's work concerns the trial of new varieties of crop plants, and the farmer who takes advantage of the frequent reports issued by the Institute can save himself a considerable amount of time, trouble and expense in trying things out for himself. Many of the notes supplied in the present report relate to types which are still only in the early stages of trial, but are none the less interesting because of that fact. At a time when high production per acre is a question of more than usual importance, the Institute's tests of the ability of certain varieties of wheat to respond to high levels of manuring without lodging will be followed with particular interest. The report indicates that seed of a carefully purified stock of SprattArcher barley and of a selected high-yielding strain of Rivet wheat have been recently made available to the seed trade.

\section{Royal Geographical Society Awards}

The King has approved the award of the Royal Medals of the Royal Geographical Society as follows : Founder's Medal to Mr. and Mrs. Harold Ingrams, for their exploration, travel, and studies in the Hadhramaut; Patron's Medal to Lieutenant Alexander R. Glen, for his expeditions in Spitsbergen and North-East Land. The Council has made the following awards: Victoria Medal to Mr. O. G. S. Crawford, for his archæological maps prepared for the Ordnance Survey and his work on the Tabula Imperii Romani; Murchison Grant to Mr. Peter Mott, for his surveys in West Greenland; Back Grant to Mr. Gerald Seligman, for his glacier studies on the Jungfraujoch; Cuthbert Peek Grant to Mr. John Hanbury-Tracy, for his work in south-eastern Tibet with Mr. Kaulback and his journey in the north of South America; Gill Memorial to Mr. Alexander King, for his work in Jan Mayen in 1938.

\section{Lectures on Food and its Use}

A SERIEs of lectures under the general title "The Nation's Larder" have been arranged at the Royal Institution with the approval and support of the Ministry of Food. The first was delivered on April 23 by Prof. J. C. Drummond, who spoke on food in relation to health in Great Britain during the past two hundred years. The remaining lectures of the series, which are being given on Tuesdays at 5.15, are on medical aspects of the use of foods (Sir Robert McCarrison), national food requirements (Sir John Orr), home production of food (Sir Frederick Keeble), manufacture, preservation and distribution of fool (Dr. L. H. Lampitt), food and the housewife (Prof. V. H. Mottram) and the feeding of children (Dr. J. C. Spence). The lectures are to be published later in book form. Admission is by ticket obtainable, free of charge, from the Royal Institution, Albemarle Street, London, W.1.

\section{Eighth American Scientific Congress}

AN illustrated descriptive programme is now available of the Eighth American Scientific Congress, to be held in Washington, D.C., during May 10-18 (see NAture, December 23, 1939, p. 1056). The Congress will be opened by President Roosevelt on May 10 ; and the first plenary session takes place on May 13. 
Sectional meetings of the eleven sections occupy the remainder of the week, and the final plenary session will be on May 17. Government delegates of the other American Republies will be entertained by the United States Government at an official luncheon and at a banquet. The headquarters of the Congress will be at the Pan American Union, Washington.

\section{Recent Earthquakes}

ON April 13 there were further aftershocks of the Anatolian earthquake of December 26, 1939, in the region originally affected. The shocks were strong and felt as far away as Ankara. Great damage was caused to fifteen villages, six being completely destroyed. Sixteen persons were injured and four children are believed to have been buried beneath the wreckage. In the Caucasus, according to a report in The Times, the River Kars has overflowed, causing damage to the town of Kars. It is conceivable that with such extensive disasters as Turkey has recently suffered there may be some ground tilting even as far distant from the scene of the original disaster as the Caucasus.

On the night of April 17, a severe earthquake was experienced at Patras at the entrance to the Gulf of Corinth and to the north of the Island of Morea. No information is available as to the damage caused, if any, at the time of writing. The earthquake was felt in the Agrinion district, and more severely in the Missolonghi district, where in 1824 the poet Byron died fighting for Greek independence. It is well known that minor earthquakes are common in Greece, and destructive ones are by no means uncommon. It will be remembered that on April 22, 1928, at about 20h. 14m. G.M.T., a severe earthquake somewhat to the north of Corinth partly destroyed that city. More information is required before the epicentre of the present shock can be accurately determined.

\section{The Night Sky in May}

By the middle of May, the night (sunset to sunrise, London) is of $8 \frac{1}{2}$ hours' duration. 'The moon is new on May 7 at 12h. and full on May 21 at 13h. Mars is in conjunction with the moon on May 10 and Venus on May 11. Jupiter and Saturn are now both morning stars but too close to the sun for observation. Venus is the brilliant evening star, setting less than one hour before midnight U.T. (that is, 1h. summer time). Its greatest brightness is reached about May 20, when its magnitude is $-\mathbf{4} \cdot \mathbf{2}$. Under favourable atmospheric conditions, it should be possible to see the planet in the daytime. Its time of meridian passage and altitude is given for May 5, 12, 19 and 26 $-15 \mathrm{~h}$. 3m. $\left(65 \cdot 8^{\circ}\right)$, 14h. 58m. $\left(65 \cdot 7^{\circ}\right)$, 14h. $49 \mathrm{~m}$. $\left(65 \cdot 2^{\circ}\right)$ and $14 \mathrm{~h} .35 \mathrm{~m} .\left(64 \cdot 5^{\circ}\right)$. A telescopic view of Venus at this time will show the planet as a crescent, $\frac{1}{3}$ full in the middle of May and $\frac{1}{5}$ full at the end. Venus, with respect to size and mass, is almost the twin of the earth. A dense atmosphere evidently surrounds the planet and screens its surface from observation. Direct telescopic scrutiny shows almost a complete absence of markings, but ultra-violet photographs have recorded belts and bright spots which are probably high-level phenomena. Thus the rotation period of the planet remains in doubt, though probably one rotation takes nearly a month. Venus is the cynosure of the western evening sky, but as night comes on a glance may be spared for the stars Capella, Procyon, Castor and Pollux in the west ; Regulus and Arcturus on the opposite side of the southern meridian; Spica low in the south, while Vega is above the north-eastern horizon. About May 4, members of the Eta Aquarid meteor shower (believed to be associated with Halley's Comet) may be seen in the early morning. On May 25, the 4th magnitude star, $p$ Sagittarii, is occulted by the moon, the disappearance as seen from Greenwich taking place at $1 \mathrm{~h} .23 \cdot 1 \mathrm{~m}$. at $90^{\circ}$ from the north point of the moon's image ; the reappearance being at $2 \mathrm{~h} .40 \cdot 9 \mathrm{~m}$. at position angle $253^{\circ}$.

\section{Announcements}

Dr. Stanley B. Bagley has been elected president of the Society of Glass Technology in succession to Dr. C. J. Peddle.

IT is announced in Science that Prof. F. Joliot and Madame Irene Curie-Joliot, co-workers in the Radium Institute, Paris, have been awarded the 1940 Barnard Gold Medal for "meritorious service to science" bestowed by Columbia University every five years. The medal was established by the will of Frederick A. P. Barnard, president of Columbia during 1864-1889, and is awarded "to the person, if any, whether a citizen of the United States or any other country, who within the five years next preceding has made such discovery in physical or astronomical science, or such novel application of science to purposes beneficial to the human race, as in the judgment of the National Academy of Sciences of the United States is esteemed most worthy of such honor'.

IN future the identification tag that every soldier in the German army must wear round his neck must indicate the blood group to which he belongs.

Migration during 1939 increased the population of Australia by 12,537 persons, 1,636 of these being British. German nationals-almost all refugeesnumbered 4,857. The gain to Australia of British migrants is the largest since 1929 , when the depression stopped assistance to immigrants.

According to La Riforma Medica of February 10, the annual birth-rate per 1,000 inhabitants in the chief capitals is as follows: Rome, 22; Buenos Aires, 18 ; Copenhagen, Budapest and Amsterdam, 15 ; New York, Berlin and London, 14 ; Warsaw, 13 ; Paris and Stockholm, 11; and Brussels, 10.

Erratum. Nature, January 27, p. 148, letter entitled "First Benedicks Effect in Gas-free Mercury, as Influenced by the Mean Temperature", for the formula $u=\mathrm{K} \cdot \frac{3}{\Delta t}$ read $u=K \cdot \overrightarrow{\Delta t}^{\text {a }}$. 